Central European Journal of Energetic Materials, 2016, 13(1), 161-182

ISSN 1733-7178

e-ISSN 2353-1843

\title{
Thermobaric Effects of Cast Composite Explosives of Different Charge Masses and Dimensions
}

\author{
Danica SIMIĆ ${ }^{1 *}$, Uroš ANDJELIĆ ${ }^{1}$, Dragan KNEŽEVIĆ ${ }^{1}$, \\ Katarina SAVIĆ ${ }^{1}$, Vladimir DRAGANIĆ ${ }^{1}$, \\ Radoslav SIROVATKA $^{1}$, Ljubiša TOMIĆ ${ }^{2}$ \\ ${ }^{1}$ Military Technical Institute, Ratka Resanovića 1, \\ 11000 Belgrade, Serbia \\ ${ }^{2}$ Technical Test Centre, Vojvode Stepe 445, \\ 11000 Belgrade, Serbia \\ *E-mail:simic_danica@yahoo.com
}

\begin{abstract}
The aim of this research was to determine the thermobaric effect of cast composite explosives, with different masses and dimensions of the chosen explosive charges. This was done by measuring the shock wave parameters in air (maximum overpressure and pressure impulse) and quantifying the thermal effect (temperature-time dependence), at different distances from the centre of the detonation. The chosen thermobaric explosive composition, TBE-3, was characterized. Its density, detonation velocity and viscosity-time dependence were determined. Experimental samples of different masses and calibres were prepared. The shock wave parameters in air were determined in field tests, by measuring the overpressure by piezo-electric pressure transducers. The detonation and the expansion of the explosion products were filmed by a TV high-speed camera, Phantom V9. An infrared (IR) camera FLIR SC7200 was used for recording the IR scene of the explosions and for tracking the thermal effects by a thermographic technique, i.e. thermal imaging. This work is an initial step towards establishing a method for the quantification of the thermal effects of a thermobaric detonation.
\end{abstract}

Keywords: shock wave in air, maximum overpressure, pressure impulse, thermal effect, infrared camera, thermal imaging 


\section{Introduction}

Thermobaric explosives (TBE) are explosive compositions that give improved incendiary and blast effects, compared to conventional high explosives. As their name indicates, they combine thermal and pressure effects (Greek: thermo $-\theta \varepsilon \rho \mu$ ó, baric $-\beta \alpha ́ \rho \rho \varsigma)$. Being mixtures of crystalline high explosives and polymeric binders, they are actually a kind of polymer bonded explosive (PBX) that belong to a group of energetic materials suitable for insensitive munitions (IM). Shock waves generated by their detonation have a much longer duration than those generated by conventional high explosives, and also have a greater lethal radius $[1,2]$. In confinement, thermobaric detonations cause a series of reflected shock waves, which maintain the fireball and can extend its duration to between 10 and $50 \mathrm{~ms}$, as exothermic recombination reactions occur. Further damage can result as the gases cool and the pressure drops sharply, leading to a partial vacuum, powerful enough to cause physical damage to people and structures. Consequently, they are highly effective for the destruction of soft targets: tunnels, bunkers, underground structures, buildings, field fabrications, etc. This kind of explosion occurs in stages. Initially, a cloud of flammable vapour or flammable metal is released (such as a mixture of finely powdered aluminium and ammonium perchlorate), and then this cloud is ignited. Effectively, it turns the air in the region of the cloud into a huge bomb. The resulting explosion has fragmentation, concussion, and incendiary elements. Actually, detonation of thermobaric explosives can be viewed as three discrete events merged together $[3,4]$ :

1. The initial anaerobic detonation reaction (microseconds in duration) defines the system's high pressure performance characteristics: armour penetrating ability;

2. Post detonation anaerobic combustion reactions (hundreds of microseconds in duration) - defines the system's intermediate pressure performance characteristics: wall/bunker breaching capability;

3. Post detonation aerobic combustion reaction (milliseconds in duration) defines the system's personnel/material defeat capability - impulse and thermal delivery.

The initial event, that is the first part of the detonation, was not tracked in the examinations presented in this work, but the second and the third stages were tracked.

Thermobaric effects are obtained by a long duration overpressure and heat due to the afterburning of the detonation products in air. Immediately after the detonation has occured, the ambient pressure increases, forming an overpressure 
pulse. The peak overpressure and positive phase duration determine the specific impulse of the blast wave. A negative phase succeeds the positive phase with its negative pressure (suction). These and other blast wave parameters can be calculated and predicted in different ways [5], but the subject of the present work is their experimental determination.

Today, cast composite thermobaric explosives most often consist of a nitramine crystalline explosive component (octogen, octahydro-1,3,5,7tetranitro-1,3,5,7-tetrazocine - HMX, hexogen, 1,3,5-trinitroperhydro-1,3,5triazine - RDX, 2,4,6,8,10,12-hexanitro-2,4,6,8,10,12-hexaazaisowurtzitane - CL-20 etc.), a polymeric binder (a telechelic liquid prepolymer such as hydroxyterminated polybutadiene - HTPB, cross linked by a curing agent a diisocyanate, plasticizer, bonding agent, and an antioxidant), a fuel component (metal powder for enhancement of the blast effect, usually aluminium - Al used in mixtures with magnesium - Mg, for more complete combustion) and an oxidizer (usually ammonium perchlorate - AP, or ammonium nitrate - AN, which provides more appropriate conditions for the oxidation of the metal powder and also for the release of larger quantities of the heat that determines the parameters of the devastating effect) [6-11].

The thermobaric effect is usually quantified by determination of the blast wave parameters and the thermal radiation surrounding the explosion site. Methods for measuring the overpressure using piezoelectric transducers were established and had been used over many years. Also, the application of fibre optic pressure sensors has been examined for the determination of the pressuretime history of explosive blasts [12]. However, temperature measurements are technically more complicated. Several investigations considering the thermal effect of the detonation have been performed recently, aiming to compare thermobaric explosives with TNT, Composition B or some other conventional explosive compositions [13-18]. Using an infrared imager, the blasting fireball's temperature from different masses of thermobaric explosive and TNT were measured. The results indicated that the thermobaric explosive possesses good thermal damage effects and that the heat radiation from the TBE fireball is much stronger than that of the conventional explosives. Thermocouples were also often used in determining the temperatures in the surrounding of an explosion site, even though there is a time lag between the thermocouple's response temperature and the explosive products' temperature. In explosive experiments in the free field response and the half-airtight space [3, 19], the results showed that thermobaric materials can provide significantly higher total energy output than conventional high explosives. C. Ludwig (Talley Defence Systems) performed a comparison of a high explosive, the well-known C-4, with a thermobaric composition in 
a reinforced enclosure, described in [3]. The recorded thermal effects from the thermobaric composition were much higher than from C-4. Absorption spectroscopy was also used in the determination of the temperature of water vapour within the expanding blast following the detonation, as a molecular thermometer to measure the dynamic thermal fields of an explosive event [20]. The dependence of the explosive effect on the sample size (regarding shock wave velocity, visible reaction i.e. fireball size, pressure history, and reaction violence) has been widely examined. The experimental examination of two high explosives - PBX-1 and Composition B, indicated that specimen size has a significant effect on the violence of the explosion [21].

The goal of the present research was to investigate the dependence of the thermobaric effect on the mass and dimensions of the explosive charge, in field tests under static conditions. The parameters of the shock wave in air were determined (maximum overpressure $\mathrm{P}_{\max }$, minimum underpressure $\mathrm{P}_{\min }$ and pressure impulse $I_{p}$ ) at different distances from the detonation centre for different masses and calibres of thermobaric explosive charges. The temperature of the fireball and the fireball's duration were determined by a thermographic technique. This was also our first attempt to record the thermal effect of the explosion using an infrared camera. The aim was to register the maximum temperature developed, the temperature change with time after the explosion and the temperature distribution in the surroundings of the detonation site. The chosen composition, TBE-3, has been the subject of previous researches and turned out to be superior to other examined compositions, giving the best results for the parameters of the shock wave in air [22], and also having good processability, i.e. viscosity-time dependence, density and porosity favourable for this kind of explosive [23].

\section{Materials and Experimental Methods}

For the purposes of this investigation, explosive charges of different masses and dimensions were prepared: $50 \mathrm{~mm}$ diameter charge without a shell ( 3 samples), and 60, 80 (2 samples each), 100 and $120 \mathrm{~mm}$ charges (3 samples each) in thin aluminium shells, height equal to twice the diameter. All of them were loaded with the chosen explosive composition, TBE-3 (HMX/AP/Al/Mg/HTPB = 45/10/21/9/15) [22, 23], prepared using the following raw materials:

- octogen (DINO - Norway), according to MIL-H-45444,

- aluminium, according to MIL-STD-129,

- magnesium (ECKA GRANULES - Austria), according to MIL-DTL-382D, 
- $\quad$ ammonium perchlorate, $7-10 \mu \mathrm{m}$, obtained by grinding $200 \mu \mathrm{m}$-AP on a vertical hammer mill ACM-10,

- polymeric binder, based on hydroxyterminated polybutadiene (Tanyun, China) cured by isophorone-diisocyanate, including additives (plasticizer, antioxidant, and bonding agent). The stochiometric ratio of the curator to binder ( $\mathrm{NCO} / \mathrm{OH}$ ratio) was 0.975 for this formulation [23-25].

The experimental explosive composition was prepared in a vertical planetary kneading machine IKA HKV-5, under vacuum, at $50{ }^{\circ} \mathrm{C}$. After homogenization, the explosive mixture was loaded directly into the previously prepared moulds and the above mentioned shells (dimensions given in Table 1), and into a further mould to provide a sample for the determination of the density and detonation velocity. After programmed cross-linking at $75^{\circ} \mathrm{C}$ for 120 hours, the explosive mixture had become a solid explosive charge with elastic-rubber characteristics. The general characteristics for the experimental composition were then determined: density, porosity, viscosity change with time and detonation velocity.

Table 1. Experimental model dimensions and average masses

\begin{tabular}{|l|c|c|c|c|c|}
\hline $\begin{array}{l}\text { Shell (charge) } \\
\text { diameter, [mm] / height, [mm] }\end{array}$ & $\varnothing 50 / 120$ & $\varnothing 60 / 120$ & $\varnothing 80 / 160$ & $\varnothing 100 / 200$ & $\varnothing 120 / 240$ \\
\hline Shell mass, [g] & - & 192.8 & 346.9 & 743.2 & 1318.5 \\
\hline Shell wall thickness, [mm] & - & 3 & 3 & 4 & 5 \\
\hline Explosive charge mass, [g] & 400 & 433.3 & 1101.7 & 2190 & 4200 \\
\hline
\end{tabular}

The influence of the TBE charge mass and dimensions on the thermobaric effects was ascertained by determining the following thermal and shock wave parameters in air:

- the value of the maximum overpressure $P_{\max }$ in the shock wave front at specific distances from the initiation of the explosive charge,

- the total positive pressure impulse $\mathrm{I}_{\mathrm{p}}$ at these distances,

- the temperature-time dependences at the different distances from the explosion centre,

- $\quad$ the maximum temperature developed.

\subsection{General characterization of the explosive}

The change in viscosity of the explosive mixture with time was determined using a Brookfield viscometer type RVT. After homogenization of the explosive mixture, a sample was taken and the viscosity was measured at $50{ }^{\circ} \mathrm{C}$ every $15 \mathrm{~min}$, with a measuring spindle speed of $5 \mathrm{~min}^{-1}$. The density of the explosive TBE-3 obtained was determined according to the method MIL $286 \mathrm{~B}$, on the 
Mohr's scale in toluene at $25^{\circ} \mathrm{C}$. The detonation velocity was measured in the zone of stable detonation in the explosive charge using electrocontact probes and an electronic counter Pendulum CNT-91.

\subsection{Determination of the shock wave in air parameters}

Experimental models for measuring the shock wave parameters (Figure 1) consisted of a TBE-3 charge, booster (plastic explosive PEP-500), detonating cap (DK N ${ }^{\circ}$ ) and safety fuse.
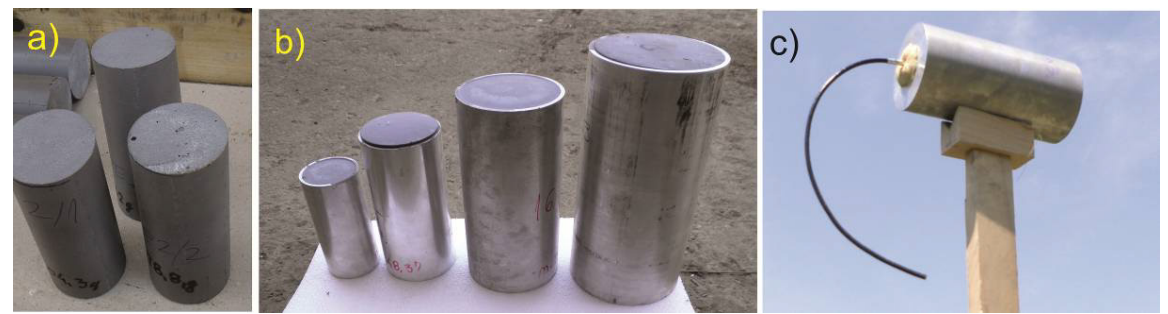

Figure 1. The explosive charges of different calibres $(\mathrm{a}, \mathrm{b})$ and the experimental model placed on a stand (c).

The parameters of the shock wave in air were determined on the range of the Technical Test Centre, in Nikinci, using the method of overpressure measurement by piezo-electric pressure transducers, i.e. gauges. The dependences of overpressure-time ( $p$-t diagrams) were obtained by software processing of the recorded signals. The basic parameters were determined: $\mathrm{P}_{\max }$ and $\mathrm{I}_{\mathrm{p}}$. The arrangement for the experiment is illustrated in Figure 2. To record the time dependence of the shock wave overpressure in air, the piezoelectric transducers were placed at specified distances from the centre of initiation: 3, 5, 7, 9 and $11 \mathrm{~m}$ from the explosive charge, at a height of $2 \mathrm{~m}$ above the ground. The receiving surfaces of the probes were placed perpendicular to the direction of propagation of the shock wave front, thus avoiding reflection of the waves on the inverter surface. The explosive charges were also placed at a height of $2 \mathrm{~m}$ above the ground (to avoid reflected waves from the ground), so that their axes were parallel to the ground and perpendicular to the line of the set of probes. It is well known that a shock wave reflected from the ground travels through an environment that was heated by the primary shock wave, and therefore is faster than the primary shock wave. At some point it overruns the primary wave and they form a united shock wave front (Mach reflection, Mach effect, Figure 3) [26-28]. In previous studies [22] it was noted that the occurrence of secondary and tertiary waves caused by reflection does not affect the maximum value of the 
primary wave overpressure at any measuring point, but it prolongs the period of the positive pressure phase, $\tau+$, so it affects the value of the total impulse over long distances.

The explosions were recorded by a high-speed camera Phantom V9.1, placed at a safe distance from the detonation site. The first recording helped to determine the best setup for the IR camera (estimation of the size of the blast fireball, i.e. approximate determination of the location for recording).

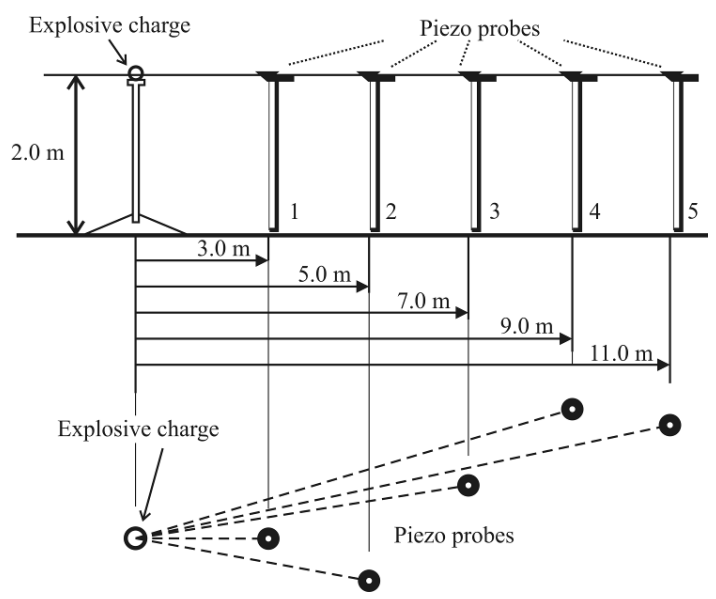

Figure 2. Scheme for the experimental determination of the shock wave parameters.

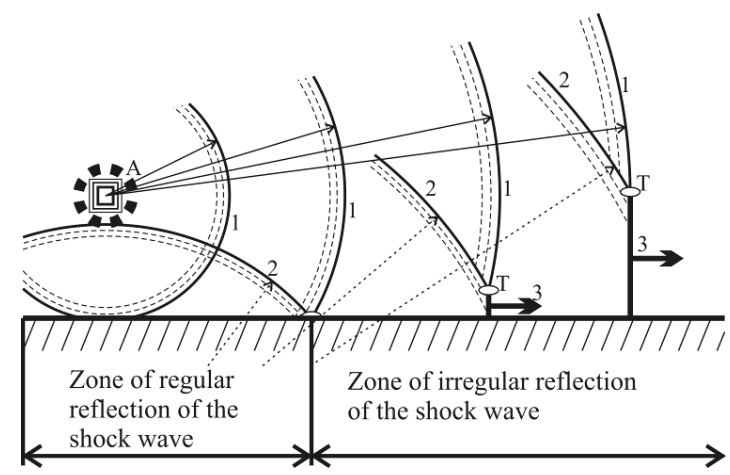

Figure 3. Mach reflection scheme (A - centre of detonation, 1 - incident wave, 2 - reflected wave, 3 - Mach front, $\mathrm{T}$ - triple point). 


\subsection{Thermal effects measurements}

An infrared (IR) camera FLIR SC7200 was used for recording the IR scene of the explosions. The camera characteristics are given in Table 2. Software "Altair" was used for data acquisition and analysis. For safety reasons the camera was placed $50 \mathrm{~m}$ away from the centre of explosion. A $50 \mathrm{~mm}$ objective was used, and the field of view was digitally narrowed down as needed. The range was manually adjusted (reduced) for each experiment so that the desired spectra could be acquired. The camera was calibrated so it could perform measurements in three different temperature sub-ranges: $5-300{ }^{\circ} \mathrm{C}$ (TR-1), 300-1500 ${ }^{\circ} \mathrm{C}$ (TR-2) and $1500-2500{ }^{\circ} \mathrm{C}$ (TR-3). Measurements which exceeded these above mentioned ranges were extrapolated by the camera software. The equipment was set-up accurately and tested on the range before performing the experiments.

Table 2. Characteristics of the FLIR SC7200 camera

\begin{tabular}{|c|c|c|}
\hline \multicolumn{2}{|l|}{ Spectral range } & $1.5-5.1 \mu \mathrm{m}$ \\
\hline \multicolumn{2}{|l|}{ Screen resolution } & $320 \times 256$ \\
\hline \multicolumn{2}{|l|}{ Camera sensitivity (NETD) } & $<20 \mathrm{mK}$ \\
\hline \multicolumn{2}{|l|}{ Aperture } & $\mathrm{F} / 3$ \\
\hline \multicolumn{2}{|l|}{ Pitch } & $30 \mu \mathrm{m}$ \\
\hline \multicolumn{2}{|l|}{ Technology } & $\mathrm{In}-\mathrm{Sb}$ \\
\hline \multicolumn{2}{|l|}{ Objective } & $50 \mathrm{~mm}$ \\
\hline \multicolumn{2}{|l|}{ Field of view angle of objective used } & $11^{\circ} \times 8.8^{\circ}$ \\
\hline \multicolumn{2}{|l|}{ Total calibrated temperature range } & $5{ }^{\circ} \mathrm{C}-2500^{\circ} \mathrm{C}$ \\
\hline \multirow{3}{*}{ Calibrated temperature subranges } & TR-1 & $5-300{ }^{\circ} \mathrm{C}$ \\
\hline & TR-2 & $300-1500^{\circ} \mathrm{C}$ \\
\hline & TR-3 & $1500-2500^{\circ} \mathrm{C}$ \\
\hline
\end{tabular}

The measuring points were chosen at specified distances: at 2, 3,6 and $9 \mathrm{~m}$ from the explosion centre. The duration and spatial distribution of the thermal effect in the vicinity of the detonation centre were observed and compared for explosive samples of different calibres.

For recordings in the TR-1 and TR-2 ranges, the picture acquisition frequency used was $174 \mathrm{~Hz}$, so the calculated frame rate was 5.75 milliseconds. In that time interval between two frames, the temperature at $2 \mathrm{~m}$ radius should reach its maximum value. This means that, just after detonation, the first frame of any recording in that frequency range should show a maximum temperature within the $2 \mathrm{~m}$ radius, and every subsequent frame should show a decrease in the temperature value. For a larger radius the maximum does not have to be in the first frame. 
Trial recordings were made with $50 \mathrm{~mm}$ charges. The aim was to prepare the measuring and recording parameters for the subsequent charges, and to view the explosion process in different temperature ranges. The temperature distribution recording during explosive decomposition of trial samples was performed at $174 \mathrm{~Hz}$. Subsequently, two recordings were made on two samples for every charge diameter, one in TR-1 and one in TR-2. However, for the $120 \mathrm{~mm}$ charges, one recording was made in TR-2 and one in TR-3.

\section{Results and Discussion}

\subsection{General characteristics of TBE-3}

The viscosity values obtained are given in Table 3 and the viscosity-time dependence for the TBE-3 composition indicated good rheological properties it showed a moderate viscosity increase with time, so TBE-3 remains castable for long enough, i.e. has a favourable processing time.

Table 3. Viscosity-time dependence for TBE-3

\begin{tabular}{|l|c|c|c|c|c|c|}
\hline Time, $[\mathrm{min}]$ & 15 & 30 & 45 & 60 & 75 & 90 \\
\hline Viscosity, $[\mathrm{Pa} \cdot \mathrm{s}]$ & 217.6 & 225.6 & 241.6 & 257.6 & 273.6 & 286.4 \\
\hline
\end{tabular}

The density and detonation velocity results are given in Table 4 . It can be noted that the measured density is very close to the theoretical value $\left(1.734 \mathrm{~g} / \mathrm{cm}^{3}\right)$, and that the detonation velocity is high enough for this type of explosive [9, 22].

Table 4. General characteristics of TBE-3

\begin{tabular}{|l|c|}
\hline Sample/Properties & TBE-3 \\
\hline Measured density & $1.702 \mathrm{~g} / \mathrm{cm}^{3}$ \\
\hline Velocity of detonation & $7154 \mathrm{~m} / \mathrm{s}$ \\
\hline
\end{tabular}

\subsection{The parameters of the shock wave in air}

For all of the calibres tested, the diagrams of $\Delta \mathrm{p}=\mathrm{f}(\mathrm{t})$ were similar - after a sharp peak at the beginning, the maximum overpressure decreased rapidly (the largest drop was registered in the region near the blast centre, 3-5 m), followed by a region in which this decrease was more moderate (7-11 $\mathrm{m}$ ). An illustrative example of the pressure-time diagrams obtained (for calibres 60 and $100 \mathrm{~mm}$, at the points 3 and $7 \mathrm{~m}$ ), is shown in Figure 4. Since the two detonations occurred at different points of time, their overpressure jumps occurred at different starting times, but in order to perceive the differences in the curves, their initiations were 
brought to the same starting position, i.e. their timelines were merged into one. Reflected shock waves were registered at both measuring points, for both charges.
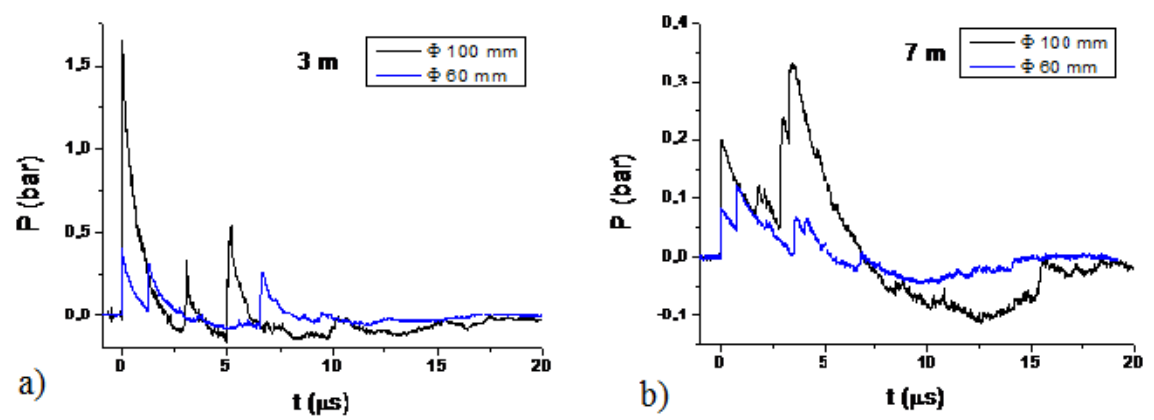

Figure 4. Dependences $\Delta \mathrm{p}=\mathrm{f}(\mathrm{t})$ for 60 and $100 \mathrm{~mm}$ charges at distances of 3 and $7 \mathrm{~m}, \mathrm{a}$ ) and $\mathrm{b}$ ), respectively.

The maximum overpressures at the measuring points, $\mathrm{P}_{\max }$ were determined, and their average values are given in Table 5. Figure 5 shows graphically the changes of $\mathrm{P}_{\max }$ as a function of distance from the explosion site. At the higher distances $(9-11 \mathrm{~m})$ there were small differences between the values of the maximum overpressure, so the influence of the explosive charge mass and dimensions on the values of $\mathrm{P}_{\max }$ is most pronounced in the region near the detonation site (measuring points 3 and $5 \mathrm{~m}$ ). The largest overpressure values at all measuring points were obtained with the largest charge, $120 \mathrm{~mm}$, and the lowest with the $60 \mathrm{~mm}$ charge. The $120 \mathrm{~mm}$ charge shows a high overpressure value at $7 \mathrm{~m}$, due to the reflected waves. A bare charge of $50 \mathrm{~mm}$ diameter shows better results than a $60 \mathrm{~mm}$ charge due to the fact that the $60 \mathrm{~mm}$ charge was in an aluminium shell, and a significant part of the detonation energy was used on its destruction.

Table 5. Maximum overpressure, $\mathrm{P}_{\max }$ of the explosive composition examined

\begin{tabular}{|c|c|c|c|c|c|}
\hline \multirow{2}{*}{$\begin{array}{c}\text { Distance from } \\
\text { explosive charge } \\
{[\mathrm{m}]}\end{array}$} & \multicolumn{5}{|c|}{$\mathrm{P}_{\max }$ [bar] for different charge diameters } \\
\cline { 2 - 6 } & $\varnothing 50 \mathrm{~mm}$ & $\varnothing 60 \mathrm{~mm}$ & $\varnothing 80 \mathrm{~mm}$ & $\varnothing 100 \mathrm{~mm}$ & $\varnothing 120 \mathrm{~mm}$ \\
\hline 3 & 0.664 & 0.449 & 0.794 & 1.423 & 1.740 \\
\hline 5 & 0.209 & 0.148 & 0.246 & 0.385 & 0.559 \\
\hline 7 & 0.211 & 0.147 & 0.199 & 0.308 & 0.584 \\
\hline 9 & 0.117 & 0.093 & 0.154 & 0.214 & 0.367 \\
\hline 11 & 0.092 & 0.086 & 0.134 & 0.184 & 0.261 \\
\hline
\end{tabular}




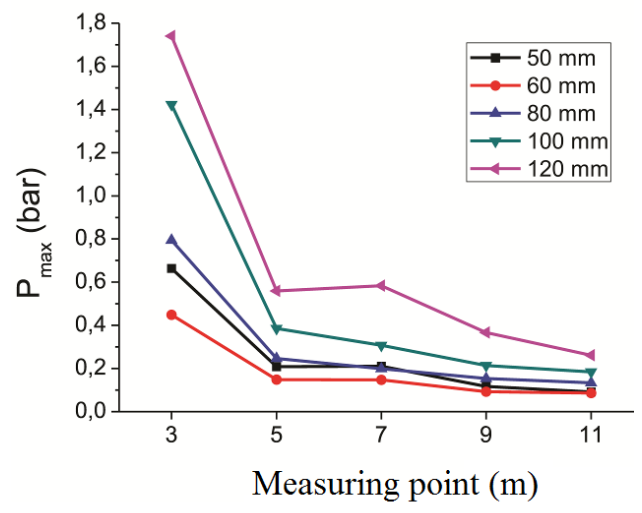

Figure 5. Dependence $\Delta \mathrm{P}_{\max }=\mathrm{f}(\mathrm{r})$ for different calibres

As previously mentioned, the appearance of the reflected wave significantly reduced the reliability of the determination of the duration of the positive blast wave phase $\left(\tau_{+}\right)$, and thus of the calculation of the impulse, $I_{p}$, particularly at measurement points distant from the explosion centre. The pressure impulse was calculated as an integral of the area under the positive part of the $\Delta \mathrm{p}=\mathrm{f}(\mathrm{t})$ curve. The values of $I_{p}$ obtained are given in Table 6. Changes in the pressure impulse are plotted in Figure 6, but it is important to note that only at measuring points 3 and $5 \mathrm{~m}$, where the error in determination of the duration of the positive pressure phase is small, are these values reliable [22].

Table 6. Pressure impulse for different charge diameters

\begin{tabular}{|c|c|c|c|c|c|}
\hline \multirow{2}{*}{$\begin{array}{c}\text { Distance from } \\
\text { explosive charge } \\
{[\mathrm{m}]}\end{array}$} & \multicolumn{5}{|c|}{$\begin{array}{c}\text { Pressure impulse Ip } \times 10 \exp 3,[\mathrm{Pas}], \\
\text { for different charge diameters }\end{array}$} \\
\cline { 2 - 6 } & $\varnothing 50 \mathrm{~mm}$ & $\varnothing 60 \mathrm{~mm}$ & $\varnothing 80 \mathrm{~mm}$ & $\varnothing 100 \mathrm{~mm}$ & $\varnothing 120 \mathrm{~mm}$ \\
\hline 3 & 0.481 & 0.393 & 0.699 & 0.950 & 1.180 \\
\hline 5 & 0.293 & 0.239 & 0.446 & 0.745 & 1.258 \\
\hline 7 & 0.328 & 0.271 & 0.581 & 0.916 & 1.252 \\
\hline 9 & 0.229 & 0.189 & 0.393 & 0.631 & 0.870 \\
\hline 11 & 0.222 & 0.192 & 0.395 & 0.641 & 0.912 \\
\hline
\end{tabular}




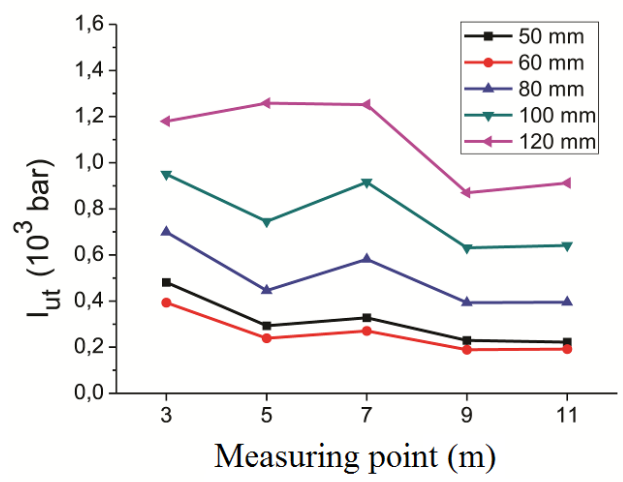

Figure 6. Dependence $\mathrm{I} p=\mathrm{f}(\mathrm{r})$ for different calibres.

The detonation and expansion of explosion products, i.e. formation of the fireball, recorded by the TV high-speed camera, are shown in Figure 7. From this first shot, the IR camera was set up to see the appropriate location for the recording of the thermal effect.

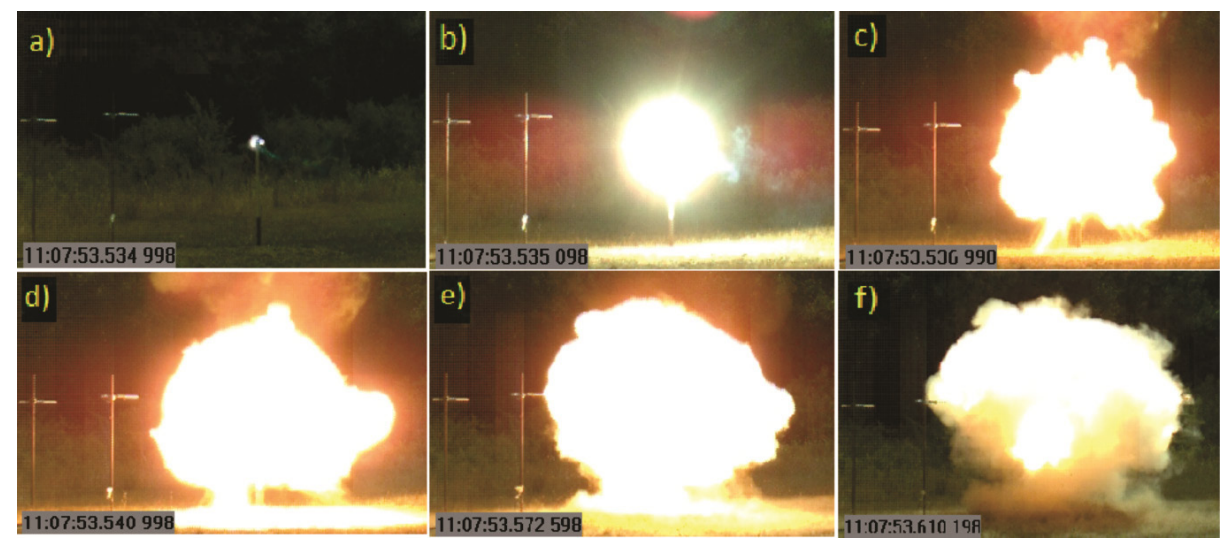

Figure 7. Detonation of TBE-3, $50 \mathrm{~mm}$ charge, and formation of the fireball, recorded by TV high-speed camera Phantom V9 (a-f).

\subsection{Thermography results}

The explosion of the test charge of $50 \mathrm{~mm}$ diameter was recorded first so that the temperature ranges (TR) could be estimated and the camera could be adjusted. The trial recordings confirmed the possibility of tracking segments of the highspeed events by thermography (Figure 8). 


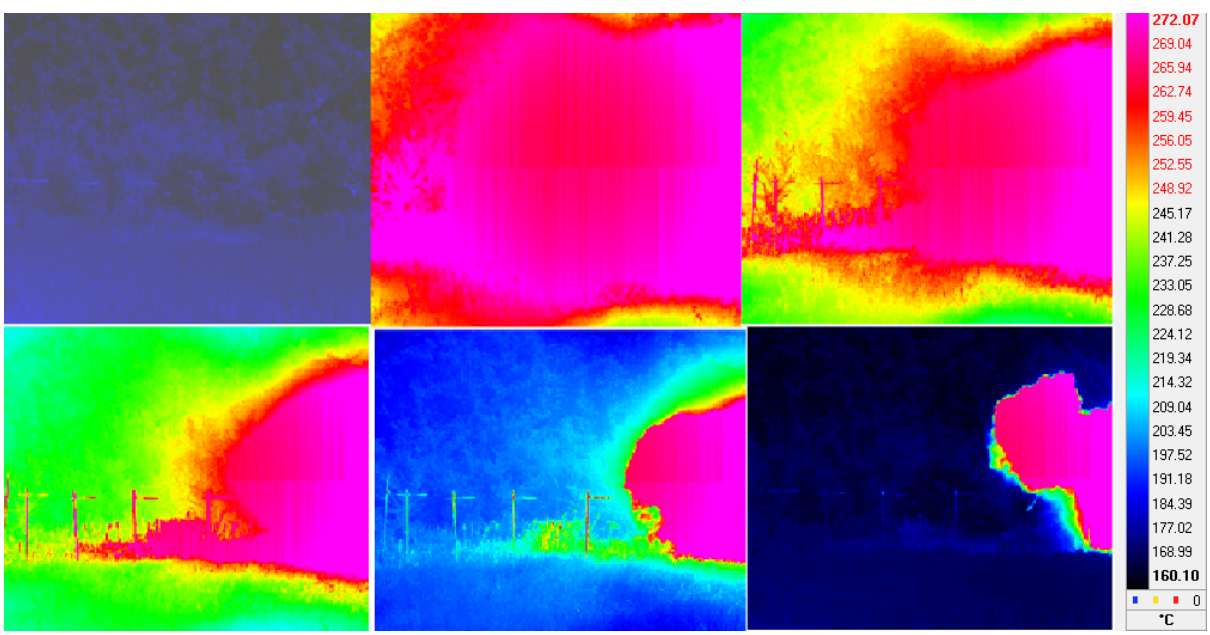

Figure 8. Detonation of a trial sample ( $50 \mathrm{~mm}$ charge), TR-1, frequency of recording: $174 \mathrm{~Hz}$.

For the recordings in TR-1, temperature-time graphs were extracted for 4 points (at 2, 3, 6 and $9 \mathrm{~m}$ distances) at the height of the explosive charge (Figure 9). For the recordings in TR-2, only 2 and 3 m recordings were extracted. The distance error from the measuring point to the explosive charge was up to $10 \%$ for all distances and all charges. The temperature ranges, maximum recorded temperatures, and the occurrence of saturation are given in Table 7.
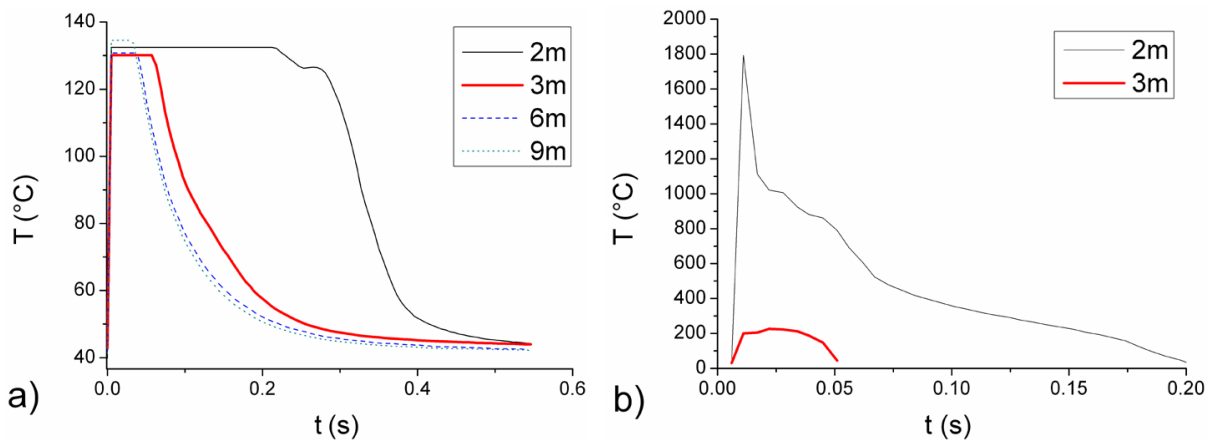

Figure 9. $50 \mathrm{~mm}$ charge recording with filter 0 (a), and filter 1 (b). 
Table 7. Maximum temperatures recorded for a $50 \mathrm{~mm}$ charge

\begin{tabular}{|l|c|c|c|c|c|c|}
\hline \multicolumn{1}{|c|}{ Temperature range } & \multicolumn{3}{c|}{ TR-1 } & \multicolumn{2}{c|}{ TR-2 } \\
\hline Distance from explosion, $[\mathrm{m}]$ & 2 & 3 & 6 & 9 & 2 & 3 \\
\hline Maximum temperature, $\left[{ }^{\circ} \mathrm{C}\right]$ & 130 & 130 & 130 & 130 & 1800 & 226 \\
\hline Saturation & yes & yes & yes & yes & yes & no \\
\hline
\end{tabular}

The upper temperature limit in the TR-1 recordings (Figure 9a) was set too low $\left(130^{\circ} \mathrm{C}\right)$, so all of the extracted temperature-time curves entered saturation. The maximum developed temperature could not be determined; it is only certain that it is much higher than the saturation temperature. One thing that can be observed from Figure 9a is that the duration of the saturation temperature for the $2 \mathrm{~m}$ distance is considerably greater than for the 3,6 and $9 \mathrm{~m}$ ones, so the maximum temperature must be highest at the $2 \mathrm{~m}$ measuring spot, and lowest at $9 \mathrm{~m}$. This observation is confirmed in Figure 9b, where the upper temperature limit was set to $1800{ }^{\circ} \mathrm{C}$ in TR-2. The $2 \mathrm{~m}$ temperature-time curve reached a peak at $1800^{\circ} \mathrm{C}$, but saturation occurred at that one particular point, so the real maximum was not recorded. The part of the curve under $500{ }^{\circ} \mathrm{C}$ was obtained by software extrapolation. Also, the whole of the $3 \mathrm{~m}$ curve was under the $500^{\circ} \mathrm{C}$ limit and was approximated entirely by the software. This means that this TR is not appropriate for measurements at $3 \mathrm{~m}$ distance from the detonation centre, i.e. the temperature-time dependence at this distance needs to be recorded in TR-1 for subsequent samples.

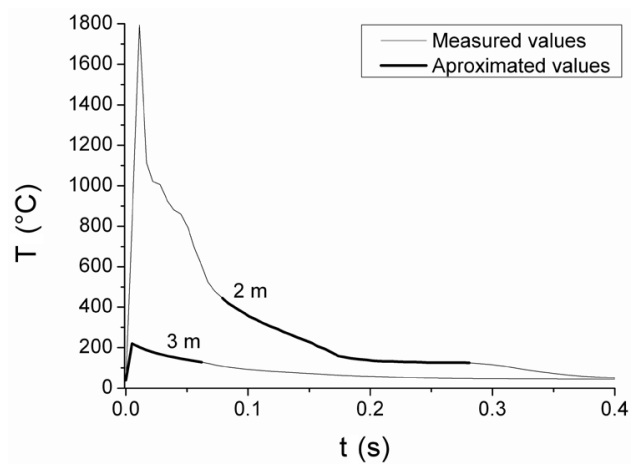

Figure 10. Combination of T-t recordings for $50 \mathrm{~mm}$ charge.

In order to encompass the full range of temperatures and to get the full picture of the thermal effect, a combination of curves (Figure 10) was made in the following way: the $2 \mathrm{~m}$ curves from Figures $9 \mathrm{a}$ and $9 \mathrm{~b}$ were combined and the small missing piece (from 0.18 to $0.21 \mathrm{~s}$ ) was added manually. The $3 \mathrm{~m}$ curve 
was taken only from Figure 9a and the maximum was approximated manually in view of the results from other diameter charges $(60,80,100$ and $120 \mathrm{~mm})$. This was possible to do due to the relatively small delay times between the considered frames extracted from the recordings, and to the negligible difference in detonation of the two samples taken with the same mass and same explosive composition. The difference in thermal effect (temperature maximum and duration) at 2 and $3 \mathrm{~m}$ distances is considerable.

For the $60 \mathrm{~mm}$ charge recordings in TR-1, temperature-time graphs were extracted for three points at 2,3, and $6 \mathrm{~m}$ distances at the height of the explosive charge (Figure 14). The $9 \mathrm{~m}$ point was out of frame. For the recordings in TR-2, again, the 2 and $3 \mathrm{~m}$ recordings were extracted. The temperature ranges, maximum recorded temperatures, and occurrence of saturation is given in Table 8 . The temperature maximum was recorded for the $2 \mathrm{~m}$ distance in TR-2, and for the 3 and $6 \mathrm{~m}$ distances in TR-1, while the $2 \mathrm{~m}$ curve recorded in TR-1 entered saturation. Again, the $3 \mathrm{~m}$ curve from the TR-2 recording fell below $500^{\circ} \mathrm{C}$. The $3 \mathrm{~m}$ curve from the recording in TR-1 showed some deviation from a smooth evolution from 0.14 to $0.4 \mathrm{~s}$ due to the randomness of the detonation expansion. The $2 \mathrm{~m}$ curve from the recording in TR-2 had a $596{ }^{\circ} \mathrm{C}$ maximum. This maximum and the smoothness of the curve around the maximum are due to the fact that the $60 \mathrm{~mm}$ charge, unlike the $50 \mathrm{~mm}$ one, is encased in an aluminium shell. Some of the detonation energy is lost to heating and breaking of this shell. This effect is reduced as the charge diameter increases because the explosive mass/shell thickness ratio increases. Another reason for the low maximum could be the randomness of the detonation expansion and the low recording frequency (the camera could miss the maximum temperature between two frame recording frames). The combination of curves was made as for the one from the $50 \mathrm{~mm}$ charge curves. The only approximation was the section from 0.08 to $0.12 \mathrm{~s}$ on the $2 \mathrm{~m}$ curve. The resulting curves are shown in Figure 11.

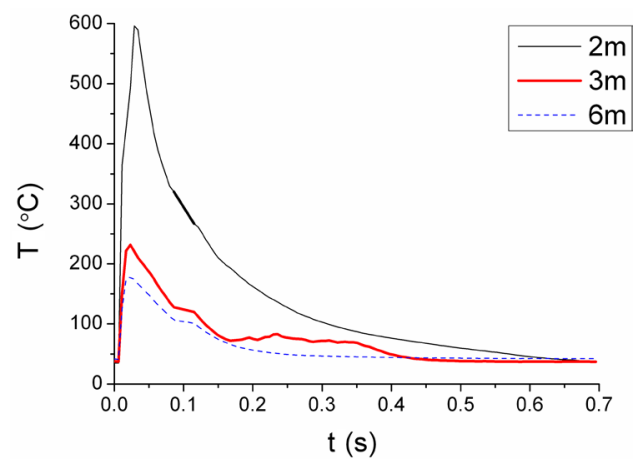

Figure 11. Combination of T-t recordings for $60 \mathrm{~mm}$ charge. 
For the $80 \mathrm{~mm}$ charge, the same points were extracted as with the $50 \mathrm{~mm}$ charge. The combination of curves was also made in a similar manner to the one for the $50 \mathrm{~mm}$ charge. The resulting curves are shown in Figure 12.

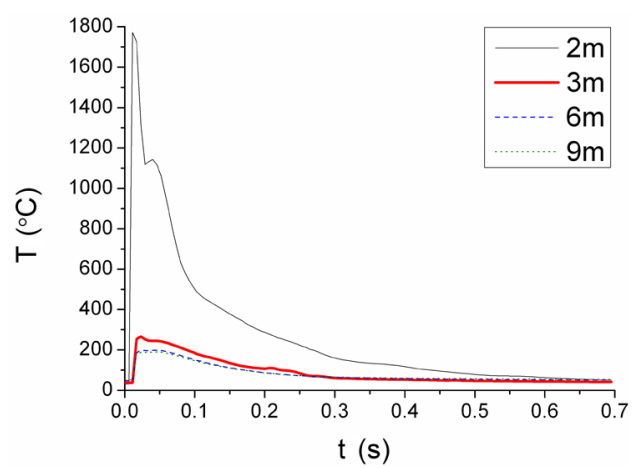

Figure 12. Combination of $\mathrm{T}-\mathrm{t}$ recordings for $80 \mathrm{~mm}$ charge.

For the $100 \mathrm{~mm}$ charge, the same points were extracted. This time the $3 \mathrm{~m}$ curves were combined and no manual approximations were made. The resulting curves are shown in Figure 16.

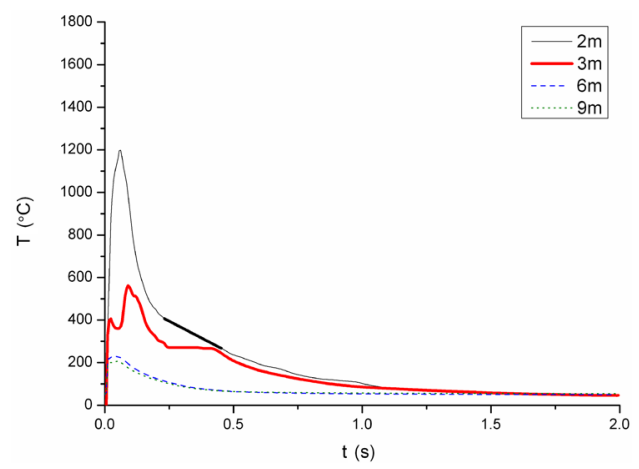

Figure 13. Combination of T-t recordings for $100 \mathrm{~mm}$ charge.

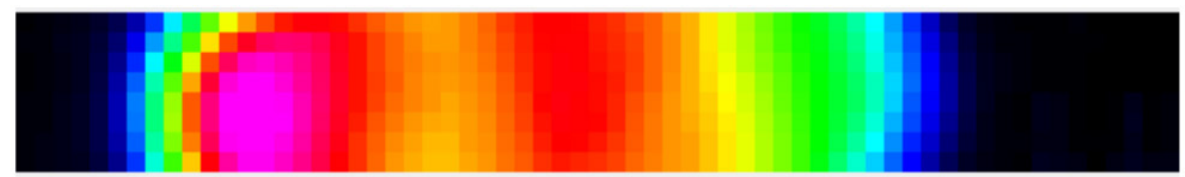

Figure 14. Recording of $120 \mathrm{~mm}$ charge detonation made in TR-3 at $5 \mathrm{kHz}$ frequency (second frame). 
For the $120 \mathrm{~mm}$ charge, two recordings were made, one in TR-2 and one in TR-3. The TR-3 recording (Figure 14) was made at a frequency of $5000 \mathrm{~Hz}$ ( $0.2 \mathrm{~ms}$ frame rate), but the field of view was considerably narrowed down so that the only point taken for the temperature-time curve was at $0 \mathrm{~m}$ distance from the charge, i.e. on the explosive itself.

Figure 15a shows that the $3 \mathrm{~m}$ curve maximum was higher than the $2 \mathrm{~m}$ one. The reason for this is, most likely, the randomness of the explosion. The curve from Figure $15 \mathrm{~b}$ shows that the maximum was very sharp at the centre of the explosion, i.e. in the explosive itself. Saturation was present at that particular point which was expected, since the detonation temperature of the explosive used reaches up to $4000{ }^{\circ} \mathrm{C}$.
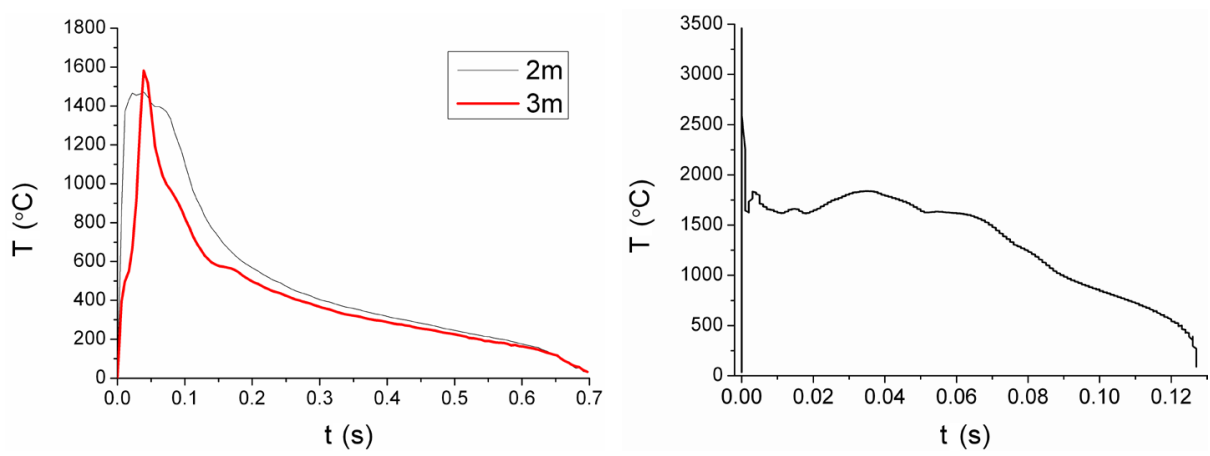

Figure 15. Recordings in TR-2 (a), and TR-3 (b), for a $100 \mathrm{~mm}$ charge.

The combined T-t curves of the charges examined for the measuring point at $2 \mathrm{~m}$ are compared in Figure 16.

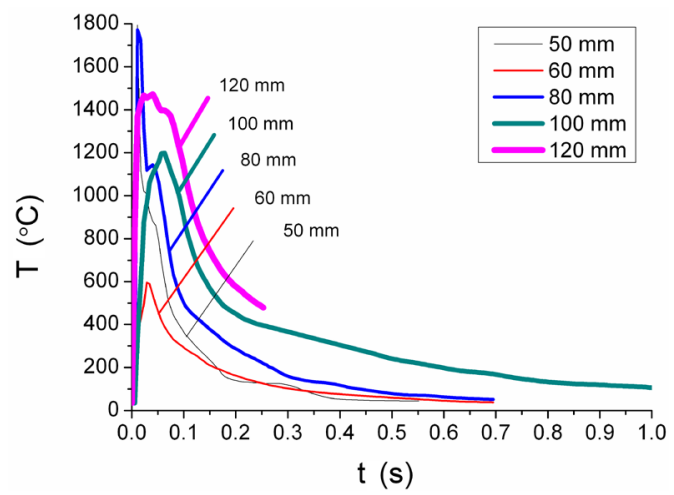

Figure 16. Comparison of T-t recordings for the $2 \mathrm{~m}$ measuring point. 
Table 8. Maximum temperatures for the charge detonations examined

\begin{tabular}{|c|c|c|c|c|}
\hline Sample calibre & $\begin{array}{c}\text { Temperature } \\
\text { range }\end{array}$ & $\begin{array}{c}\text { Distance from } \\
\text { detonation centre } \\
{[\mathrm{m}]}\end{array}$ & $\begin{array}{l}\text { Saturation } \\
\text { presence }\end{array}$ & $\begin{array}{c}\text { Maximum } \\
\text { temperature } \\
{\left[{ }^{\circ} \mathrm{C}\right]}\end{array}$ \\
\hline \multirow{5}{*}{$60 \mathrm{~mm}$} & \multirow{3}{*}{ TR-1 } & 2 & yes & 270 \\
\hline & & 3 & no & 232 \\
\hline & & 6 & no & 178 \\
\hline & \multirow{2}{*}{ TR-2 } & 2 & no & 596 \\
\hline & & 3 & no & 228 \\
\hline \multirow{6}{*}{$80 \mathrm{~mm}$} & \multirow{4}{*}{ TR-1 } & 2 & yes & 270 \\
\hline & & 3 & yes & 266 \\
\hline & & 6 & no & 197 \\
\hline & & 9 & no & 190 \\
\hline & \multirow{2}{*}{ TR-2 } & 2 & yes & 1800 \\
\hline & & 3 & no & 543 \\
\hline \multirow{6}{*}{$100 \mathrm{~mm}$} & \multirow{4}{*}{ TR-1 } & 2 & yes & 275 \\
\hline & & 3 & yes & 275 \\
\hline & & 6 & no & 226 \\
\hline & & 9 & no & 201 \\
\hline & \multirow{2}{*}{ TR-2 } & 2 & no & 1199 \\
\hline & & 3 & no & 544 \\
\hline \multirow{3}{*}{$120 \mathrm{~mm}$} & \multirow{2}{*}{ TR-2 } & 2 & no & 1472 \\
\hline & & 3 & no & 1581 \\
\hline & TR-3 & 2 & yes & 3459 \\
\hline
\end{tabular}

It may be observed that all of the curves have a very similar shape, indicating that the detonation decomposition and afterburning process of all of the samples follow the same pattern. This indicates that, regardless of the resolution of the IR camera and the randomness of the detonation, a high level of reproducibility and coherence of the results obtained was achieved using the thermal imaging technique.

Analyzing the results shown in Figure 16 several facts should be considered:

- the $50 \mathrm{~mm}$ charge is the only one without a shell, so it cannot be compared easily with the other charges because in its case no energy is lost on shell heating and destruction,

- for the $120 \mathrm{~mm}$ charge, the $2 \mathrm{~m}$ curve is shorter than the others because no recording was made in TR-1,

- $\quad$ only the 50 and $80 \mathrm{~mm}$ charges have a sharp maximum on the $2 \mathrm{~m}$ curves (this has already been explained above as a problem with the randomness 
of the explosion and the relatively low recording frame rate).

Taking these facts into consideration, it is generally clear that the maximum temperature values and the thermal effect, increase drastically with increases in mass and diameter of the explosive charges, especially at measuring points close to the detonation site $(2-3 \mathrm{~m})$, and immediately after the explosion (up to 0.1-0.2 s). The thermal effect of the thermobaric detonation can be viewed as an integral of the temperature-time function (area below the T-t curve, Table 9). The integration limits were $0 \mathrm{~s}$ from the left, and $0.253 \mathrm{~s}$ (where the curve for the $120 \mathrm{~mm}$ charge ends).

The resulting curves given shown in Figure 16, are a consequence of the fact that a higher mass of the explosive sample gives a larger fire-ball. Also, for the larger samples, the quantity of metal powder as fuel (and other ingredients) is significantly larger. Therefore, the $\mathrm{Al} / \mathrm{Mg}$ particles are spread further from the center of detonation, so afterburning happens at longer distances, i.e. temperatures are higher at those measuring points.

Although the randomness of the explosion is a factor, the reproducibility of the recordings that was achieved shows that this factor is not dominant. The influence of the low recording frame rate cannot be easily analyzed, and it will be one of the important topics in our future work. Higher frame rate recordings have to be made while maintaining an adequate camera setup, so that reproducible results can be extracted.

Table 9. Integral of the temperature-time functions for different charge diameters

\begin{tabular}{|l|c|c|c|c|c|}
\hline \multicolumn{1}{|c|}{ Charge diameter } & $\begin{array}{c}\varnothing \\
50 \mathrm{~mm}\end{array}$ & $\begin{array}{c}\varnothing \\
60 \mathrm{~mm}\end{array}$ & $\begin{array}{c}\varnothing \\
80 \mathrm{~mm}\end{array}$ & $\begin{array}{c}\varnothing \\
100 \mathrm{~mm}\end{array}$ & $\begin{array}{c}\varnothing \\
120 \mathrm{~mm}\end{array}$ \\
\hline Integral of the T-t curve, $[\mathrm{K} \cdot \mathrm{s}]$ & 105.8 & 68.3 & 143.7 & 173.7 & 236.4 \\
\hline $\begin{array}{l}\text { Integral for temperature area } \\
\text { above } 100^{\circ} \mathrm{C},[\mathrm{K} \cdot \mathrm{s}]\end{array}$ & 80.5 & 42.9 & 118.4 & 148.4 & 211.1 \\
\hline
\end{tabular}

In addition to these values, Table 9 also gives the values obtained by subtracting the part of the integral which refers to the temperatures below $100{ }^{\circ} \mathrm{C}$ from the total integral (area subtracted from the total integral equals $0.253 \mathrm{~s} \times 100 \mathrm{~K}=25.3 \mathrm{~K} \cdot \mathrm{s})$. 


\section{Conclusions}

The chosen thermobaric composition, TBE-3 has shown desirable general properties: good rheological behaviour (a moderate viscosity increase with time, resulting in a favourable processing time), measured density very close to the theoretical value, and a detonation velocity high enough for this group of explosives.

The thermobaric effects of TBE- 3 charges of different masses and dimensions were examined, for prepared explosive charges of 50, 60, 80, 100 and $120 \mathrm{~mm}$ in diameter. The parameters of the shock wave in air were determined in field tests, at specified distances from the detonation centre. An increase in the maximum overpressure and pressure impulse with increase in charge calibre was evident. The highest maximum overpressure and the highest pressure impulse values at all measuring points were achieved for the $120 \mathrm{~mm}$ charge. At larger distances from the explosion centre, small differences in the values of these parameters were registered, which indicated that the influence of the mass and dimensions of the explosive charge on these values is most pronounced in the region close to the detonation site.

The maximum temperatures and the thermal effects, viewed as an integral of the temperature-time function, increase dramatically with an increase in mass and diameter of the explosive charge, especially at measuring points close to the detonation site, and at short times immediately after the explosion.

The thermobaric effect is most pronounced for the largest charge $-120 \mathrm{~mm}$, and lowest for the $60 \mathrm{~mm}$ charge. The charge without a shell $(50 \mathrm{~mm})$ shows better thermobaric effects than the $60 \mathrm{~mm}$ charge because it lacks the energy dissipation, present for the $60 \mathrm{~mm}$ charge.

\section{References}

[1] Wildegger-Gaissmaier A.E., Aspects of Thermobaric Weaponry, Military Technology, 2004, 28(6), 125-130.

[2] Singh H., Thermobaric Weapons - A Review, 10/12/2009; http://defstrat.com/exec/ frmArticleDetails.aspx?DID $=213$

[3] Ludwig C., Verifying Performance of Thermobaric Materials for Small to Medium Calibre Rocket Warheads, Talley Defence Systems; http://www.dtic.mil/ ndia/2003gun/lud.pdf

[4] www.globalsecurity.org/military/systems/munitions/thermobaric.htm

[5] Bajić Z., Bogdanov J., Jeremić R., Blast Effects Evaluation Using TNT Equivalent, Scientific Technical Review, 2009, 59(3-4), 50-53. 
[6] Agrawal J.P., High Energy Materials: Propellants, Explosives and Pyrotechnics, WILEY-VCH, Weinheim, 2010; ISBN 9783527326105 ; DOI: 10.1002/prep.201000098.

[7] Chan M.L., Meyers G.W., Advanced Thermobaric Explosive Compositions, US Patent No: US 6,955,732 B1, 2005.

[8] Chan M.L., Turner A.D., High Energy Blast Explosives for Confined Spaces, US Patent No. 6,969,434, 2002.

[9] Antić G., Cast Explosive Compositions for Underwater Application (in Serbian: Livene eksplozivne smeše za podvodnu primenu), Naučnotehničke Informacije, Vojnotehnički Institut Beograd, 2005.

[10] Tanguay V., Goroshin S., Higgins A.J., Zhang F., Aluminum Particle Combustion in High-speed Detonation Products, Combust. Sci. and Tech, 2009, 181(4), 670-693.

[11] Yen N.H., Wang L.Y., Reactive Metals in Explosives, Propellants Explos. Pyrotech., 2012, 37, 143-155.

[12] Watson S., MacPherson W.N., Barton J.S., Jones J.D.C., Tyas A., Pichug A.V., Investigation of Shock Waves in Explosive Blasts Using Fibre Optic Pressure Sensors, Meas. Sci. Technol., 2006, 17, 1337-1342.

[13] Guo X-Y., Li B., Xie L-F., Study on Thermal Damage of Thermobaric Explosive (in Chinese), Chinese Journal of Explosives \& Propellants, 2008, 31(1), 16-19.

[14] Li B., Guo X-Y., Xie L-F., Study on Thermal Sustaining Damage Ability of Thermobaric Explosive (in Chinese), Journal of Ballistics, 2009, 4, 99-102.

[15] Guo X.Y., Li, B., Wang, L.J., Measurement of Blast Temperature Field and Study of Thermal Radiation Effect for Thermo-baric Explosive (in Chinese), Journal of Projectiles, Rockets, Missiles and Guidance, 2008, 28(5), 119-124.

[16] Kan J.L., Liu, J.C., Zeng, X.L., Fireball Characteristics of a Thermal-Baric Explosive (in Chinese), Chinese Journal of Explosives \& Propellants, 2007, 30(2), $55-58$.

[17] Lixin X., Feng Y., Hong-zhi Y., Experimental Study on the Parameters of FAE's Temperature Field (in Chinese), Explosive Materials, 2007, 2, 6-8.

[18] Li-feng X., Zheng-wen H.E, Feng Y., Hong-zhi Y., An Experimental Study on the Parameters of FAE Temperature Field (in Chinese), Journal of Ballistics, 2007, 19(1), 48-50.

[19] Ji J.R., Su J.J., Li Z.R., Wang G.Q., Analysis of Hot Response of WRe5/26 Thermocouple to Explosive Products (in Chinese), Chinese Journal of Explosives \& Propellants, 2008, 31(1), 26.

[20] Carney J.R., Lightstone J.M., Piecuch S., Koch J.D., Water Temperature and Concentration Measurements Within the Expanding Blast Wave of a High Explosive, Meas. Sci. Technol., 2011, 22(4), 045601 (10pp).

[21] Ma D-Z., Tian Y., Li J-M., Dai K., Dai X-G., Chen P-W., Effects of Specimen Size on Impact-induced Reaction of High Explosives, Combust. Sci. Tech., 2013, 185(13), 1227-1240.

[22] Simić D., Popović M., Sirovatka R., Andjelić U., Influence of Cast Composite Thermobaric Explosive Composition on Air Shock Wave Parameters, Scientific Technical Review, Belgrade, 2013, 63(2), 63-69. 
[23] Simić D., Petković J., Milojković A., Brzić S., Influence of Composition on Thermobaric Explosives Processability, Scientific Technical Review, Belgrade, 2013, 63(3), 3-8.

[24] Rodić V., Petrić M., The Effect of Additives on Solid Rocket Propellant Characteristics, Scientific Technical Review, 2004, 54(3-4), 9-14.

[25] Brzić S.J., Jelisavac Lj.N., Galović J.R., Simić D.M., Petković J.Lj., Viscoelastic Properties of Hydroxyl-Terminated Poly(Butadiene) Based Composite Rocket Propellants, Hemijska Industrija, 2014, 68(4), 435-443.

[26] Jeremić R., Explosions and Explosives (in Serbian), Vojnoizdavački Zavod, Belgrade, 2007.

[27] Le Blanc G., Adoum M., Lapoujade V., External Blast Load on Structures Empirical Approach, $5^{\text {th }}$ European LS-DYNA Users Conference, Arup, Birmingham, UK, 25th-26th May 2005.

[28] Baker W.E., Explosions in Air, Texas USA, 1973; ISBN 0-292-7200-3. 